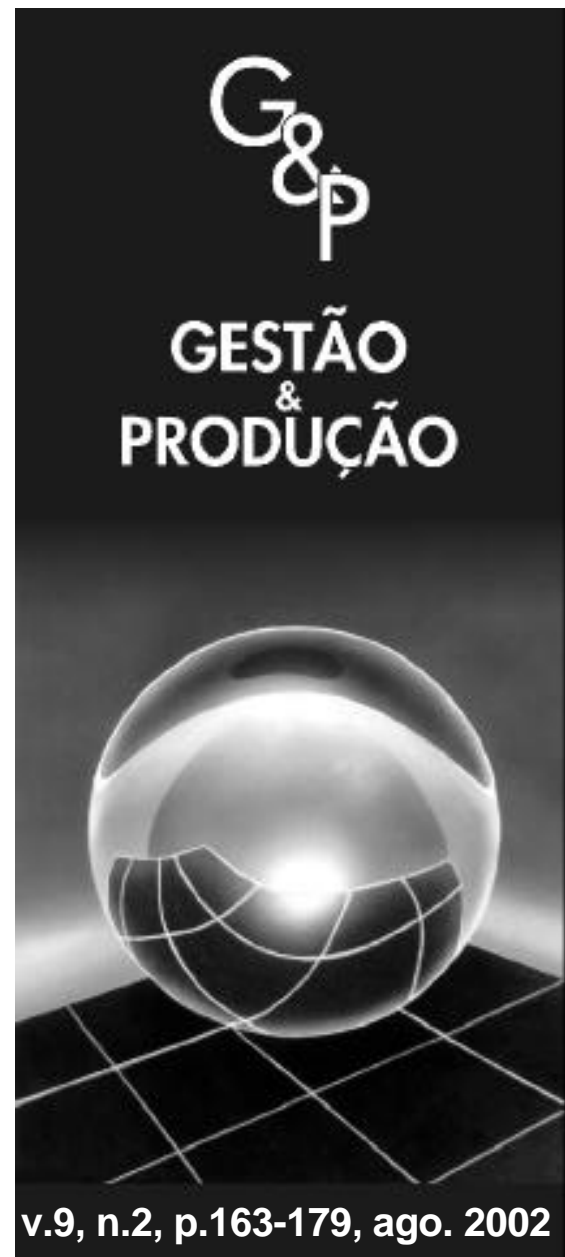

\title{
O USO DAS METODOLOGIAS "PLANEJAMENTO ESTRATÉGICO SITUACIONAL" E "MAPEAMENTO COGNITIVO" EM UMA SITUAÇÃO CONCRETA: O CASO DA PRÓ-REITORIA DE EXTENSÃO DA UFSCar
}

\author{
Denise Luciana Rieg \\ Targino de Araújo Filho
}

Departamento de Engenharia de Produção, Universidade Federal de São Carlos, C.P. 676, CEP 13565-905, São Carlos, SP, e-mails: pdlr@iris.ufscar.br, targino@power.ufscar.br

\section{Resumo}

Este trabalho volta-se para a discussão de duas metodologias de planejamento estratégico, Planejamento Estratégico Situacional (PES) e Mapeamento Cognitivo, tendo por referência a utilização destas em uma situação concreta - a gestão da Pró-Reitoria de Extensão da UFSCar (1996-2000). Nesse sentido, apresenta algumas considerações acerca dessas metodologias, quanto a seus conteúdos e estruturas, e uma discussão acerca de sua implementação e dos produtos por elas gerados nas aplicações na Pró-Reitoria. Procura, por fim, explorar algumas possibilidades de complementaridade entre as duas metodologias.

Palavras-chave: planejamento estratégico situacional, mapeamento cognitivo, estudo de caso, complementaridade.

\section{Introdução}

$\mathrm{N}$ este artigo são abordadas duas metodologias de planejamento: Planejamento Estratégico Situacional (PES) e Mapeamento Cognitivo, que surgem, ainda na década de 1970, no bojo de um movimento de emergência de abor- dagens alternativas à abordagem convencional. Visando lidar com uma série de situações para as quais as metodologias convencionais não se mostram adequadas, passam a adotar um paradigma diferente daquele adotado pelas metodologias clássicas, a subjetividade (Araújo Filho, 1994; Araújo Filho \& Fuks, 1994). 
Não é esse movimento, no entanto, o objeto deste trabalho, mas a oportunidade que os autores tiveram no sentido de vivenciar a utilização dessas duas metodologias em uma situação concreta: a gestão da Pró-Reitoria de Extensão (ProEx) da UFSCar de 1996 a 2000.

Nesse sentido, o trabalho faz primeiro uma apresentação sucinta das principais características de cada uma das duas metodologias para, então, discutir sua utilização na ProEx. Há que se ressaltar, no entanto, que, enquanto o PES foi utilizado para construir um plano para toda a gestão da UFSCar, do qual deriva um conjunto de ações para a ProEx, o mapeamento cognitivo recebeu tratamento mais aprofundado, já que, procurando enriquecer a aplicação e os produtos do PES, seu uso foi objeto de diversas experiências. Não obstante essas diferenças, foi possível desenvolver algumas comparações entre as metodologias e explorar algumas possibilidades de complementaridade entre elas.

Este trabalho tem início com uma breve apresentação acerca do PES e, em seguida, traz uma discussão sobre sua aplicação na UFSCar. $\mathrm{Na}$ sequência é apresentado o mapeamento cognitivo e, então, os mapas desenvolvidos para a gestão da ProEx, a forma como foram utilizados para enriquecer a parte do plano PES relativa à extensão, e a forma como se chegou a uma agenda para o pró-reitor nos próprios mapas. Por fim, nas considerações finais, são feitos alguns comentários sobre os resultados obtidos e apresentadas algumas possibilidades de complementaridade entre as duas metodologias.

\section{Planejamento Estratégico Situacional (PES)}

O PES, embora seja influenciado pelo trabalho de outros autores como Ackoff (1974) e Mason \& Mitroff (1981), tem em Carlos Matus seu grande mentor intelectual e maior entusiasta. Ministro de Planejamento do Presidente Allende, no Chile, Matus, a partir da queda desse governo, passou a se dedicar à compreensão do que deu errado naquela gestão. É o criador da Fundação Altadir, na Venezuela, que tem por objeto a pesquisa, o desenvolvimento e o uso de ciências e técnicas de governo. É, em função disso, um defensor intransigente da necessidade de que dirigentes políticos, estejam eles em posições de governo, partidos, sindicatos, organizações (públicas ou privadas) etc., ampliem sua capacidade de governo utilizando por instrumento de trabalho todo um conjunto de conhecimentos que denomina planejamento moderno e que tem por produto principal o PES (Matus, 1997b; Huertas, 1996).

O PES apresenta três características principais. A primeira é o subjetivismo, que tem por objetivo identificar e analisar uma situação problemática, centra-se nos indivíduos envolvidos (atores), em suas percepções e pontos de vista, pressupondo, portanto, que se cada indivíduo tem suas próprias características, sua interpretação de determinada situação vai depender de seus conhecimentos, experiências, crenças, posição no jogo social etc. Como as ações, por sua vez, surgem do significado dado a cada situação, e este varia de um indivíduo para outro, também a maneira de agir varia. Assim, o PES preconiza que não se pode planejar como se o planejador fosse o único ator, ignorando os demais envolvidos ou predizendo seus comportamentos. É necessário, portanto, diferenciar as explicações dos diferentes autores, sem ignorar nenhuma, para que se possa agir de modo eficaz (Matus, 1997b).

É em função dessa perspectiva que Matus (Huertas, 1996) argumenta que a realidade não pode ser explicada por uma simples descrição (diagnóstico), mas pelas diferentes interpretações dadas pelos atores envolvidos (apreciação situacional). Por conseguinte, o termo situacional vem do conceito de "situação", que é a chave para entender os outros atores e suas interpretações da realidade, permitindo uma ação mais eficaz no jogo social. Ressalta ainda que, nessa perspectiva (Matus, 1998), o conceito de situação exige determinar quem está explicando a realidade, uma vez que esta pode ser explicada de formas distintas, pois os diferentes atores participam do jogo social com diferentes propósitos. 
A segunda característica do PES é a elaboração de planos-proposta a partir de problemas, entendidos como obstáculos criados em razão da diferença entre a realidade atual do jogo social e as aspirações de um ator de acordo com seu mundo subjetivo. Em outras palavras, tem-se um problema quando o ator (planejador) encontra-se insatisfeito com determinada situação e ao mesmo tempo a considera evitável (Huertas, 1996).

Como terceira característica, o PES assume que o futuro é incerto, não sendo possível predizê-lo. Assim, não se prende a uma visão determinista do mundo, no sentido de predizer (adivinhar) o futuro e buscar alcançá-lo, mas busca enumerar possibilidades e preparar os atores para enfrentá-las. Como pondera Matus (Huertas, 1996), o PES é, na verdade, uma ferramenta de liberdade, pois, ao não se basear na capacidade de predição, mas na de previsão, se constitui em um cálculo que precede e preside a ação para criar o futuro, dependendo, portanto, das possibilidades de os atores serem capazes de imaginar e descobrir e da qualidade dos planos desenvolvidos. É, nesse sentido, uma aposta de caráter genuinamente estratégico, e não sobre o destino (ou o futuro), pois, à medida que se planeja, se influe no futuro.

Observa-se, então, que o PES, ao considerar a subjetividade e a incerteza sobre o futuro, realmente aumenta a complexidade com que é tratada a situação problemática sob análise, mas toda a riqueza de detalhes e diferentes perspectivas trazidas para determinada questão são vistas como elementos-chave para lidar com a mesma de maneira satisfatória (Matus, 1997b).

Para tal, o PES pode ser subdividido em quatro momentos mostrados, na Figura 1: o explicativo, que busca justificar os porquês da situação atual; o normativo, no qual se estabelece o que se deseja fazer; o estratégico, que analisa a viabilidade das operações planejadas; e o táticooperacional, que cuida da implementação das operações no dia-a-dia.

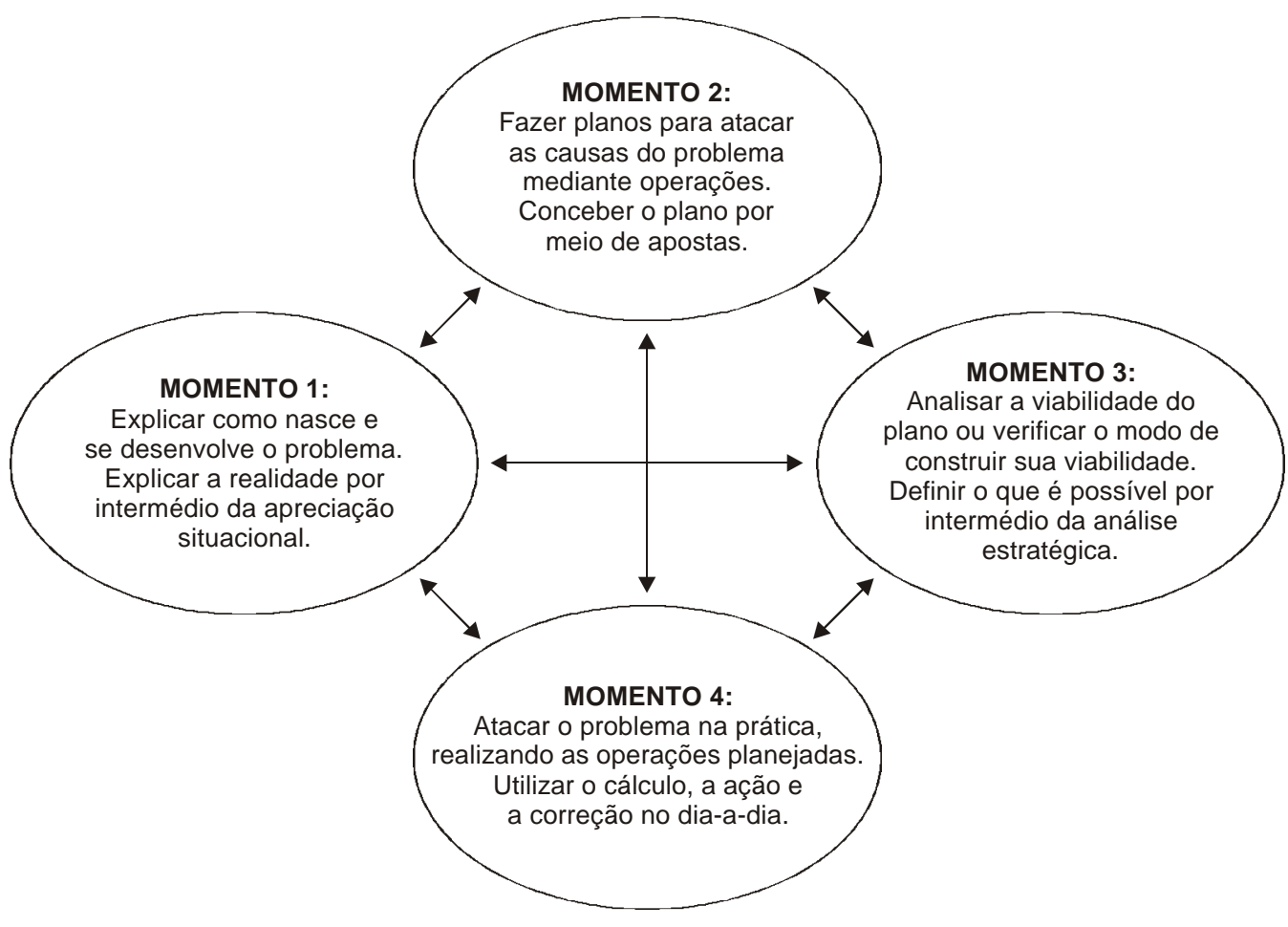

Figura 1 - Os quatro momentos do PES. 
Enquanto os três primeiros são momentos de acúmulo de conhecimentos pelo ator planejador, o quarto momento é o da ação propriamente dita. Saliente-se ainda que, embora enumerados, os momentos não devem ser vistos como consecutivos, pois, se a realidade é mutável, o plano também é, devendo o planejamento ser visto como "diário", o que significa estar constantemente trabalhando nos quatro momentos ao mesmo tempo.

Uma tentativa de síntese desses momentos leva ao seguinte. No momento explicativo, o PES volta-se para a compreensão do mundo real por meio da apreciação situacional, tendo por objetivo procurar explicar a realidade, identificando os problemas declarados pelo ator para o qual se está planejando. Trabalha-se aqui com a categoria de macroproblema, na medida em que os problemas declarados, em geral, não são isolados, mas um conjunto que coexiste e interage. É essa categoria, sintetizando os problemas parciais, que possibilita a análise conjunta.

Identificado o macroproblema, mediante a enumeração e seleção dos problemas parciais relevantes, utiliza-se o conceito de vetor de descrição do problema $\left(\operatorname{VDP}=\left(\mathrm{d}_{1}, \mathrm{~d}_{2}, \ldots\right)\right)$. Para explicar um problema é indispensável definir seu conteúdo, uma vez que este não pode ser explicado por seu "nome". Assim, o VDP é constituído de descritores $\left(\mathrm{d}_{\mathrm{i}}\right)$, o suficiente para dar precisão ao problema, que descrevem e enumeram de forma precisa os fatos que demonstram a existência do mesmo. Deve-se atentar para o fato de que nenhum descritor deve se referir a causas ou conseqüências de outro descritor (Matus, 1997b).

Estabelecido o VDP do problema, enumeram-se suas consequiências e a análise volta-se para as causas. Nessa análise dois tipos de classificação são utilizados, um que considera o tipo de causa e outro que é relativo ao grau de controle do planejador sobre as causas. Em relação às causas, tem-se que diferenciar quais são fluxos, acumulações e regras. Os fluxos são definidos como as causas imediatas do VDP (jogadas, ações, realizações etc., diretamente relacionadas aos descritores do problema), as acumulações são as diferentes capacidades ou incapacidades que produzem os fluxos (poder, influência política, condição financeira, capacidade e incapacidade de produção etc.) e as regras são o que vai dar legitimidade às causas e às acumulações no jogo social (regulamentos, leis, estímulos, proibições etc.) (Huertas, 1996).

Quanto aos graus de controle do planejador sobre as causas, o PES trabalha identificando três zonas de governabilidade: sob ou fora do controle do planejador e fora do jogo social, considerando que, quando estas se encontram fora do jogo social, encontram-se também fora do controle do planejador.

Todo esse conjunto de informações declarado pelo ator para o qual se está planejando é reunido no denominado fluxograma situacional, que é uma representação gráfica da visão desse ator sobre a situação sob análise e que permite relacionar as causas entre si e com os descritores, por meio de conexões causais. A Figura 2 apresenta este fluxograma de forma esquemática, devendo-se salientar que este, além de conter todas as relações entre os problemas (problemas/ causas), permite a distinção entre seus tipos e os tipos de governabilidade do planejador sobre os mesmos.

Construído o fluxograma, o próximo passo é identificar os nós-críticos - causas sobre as quais o ator planejador tem condições de atuar com eficácia e que têm influência direta sobre o VDP do problema - e construir uma versão simplificada do fluxograma situacional (árvore do problema), em que só aparecem as relações causais entre os nós-críticos. A forma de ataque a essas causas, no entanto, é definida no momento seguinte do PES, o normativo.

O objetivo do segundo momento “... é produzir as respostas de ação em um contexto de incertezas e surpresas" (Huertas, 1996). Deste modo, para lidar com as surpresas, imaginadas como possíveis pelo planejador, são elaborados planos de contingência.

Já para lidar com as incertezas, trabalha-se com cenários que podem ser de três tipos: teto, que traz as melhores condições sobre o futuro que o planejador consegue vislumbrar; piso, que traz as piores condições; e centro, que é o mais provável na visão do planejador. 


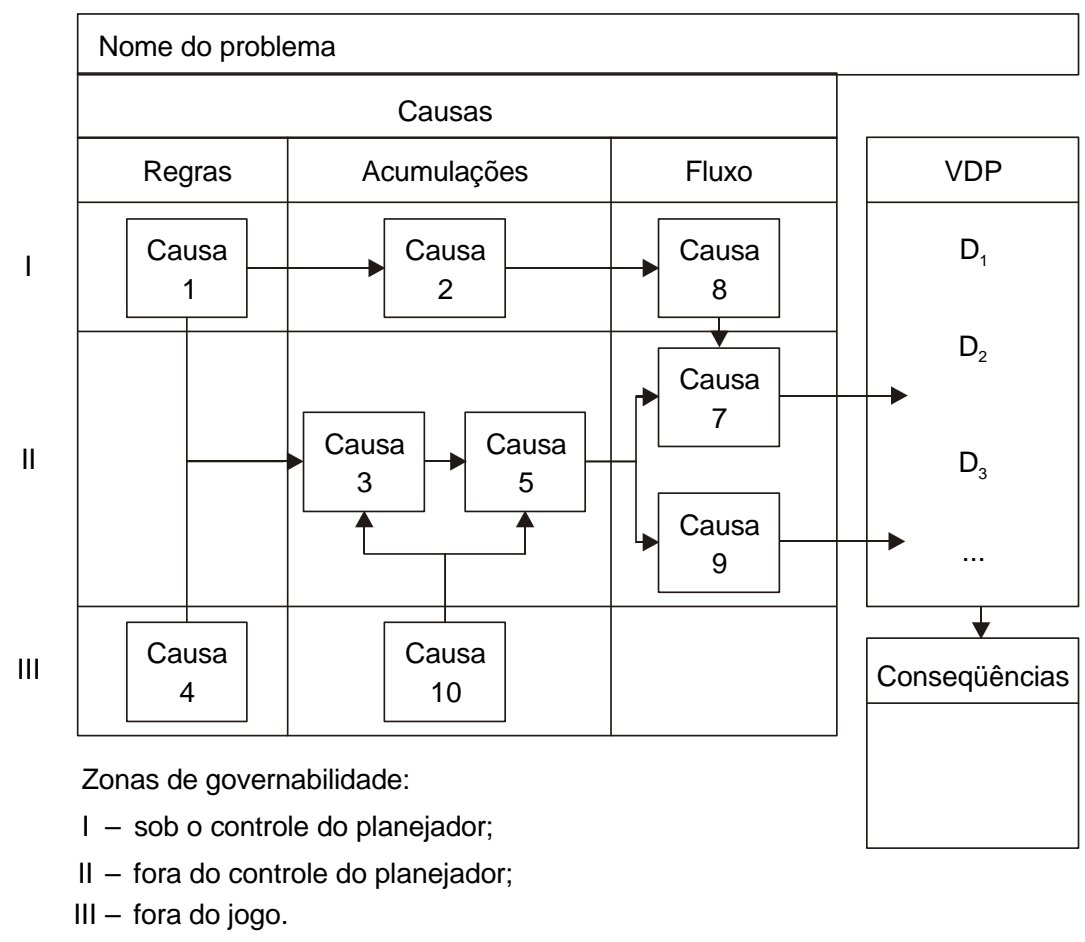

Figura 2 - Fluxograma situacional (adaptado de Matus, 1997b).

Para cada cenário constrói-se um plano a fim de atacar cada nó crítico identificado no primeiro momento. Esses planos são constituídos de operações definidas por Matus como uma “... unidade básica de ação que um ator realiza para mudar a realidade" (Huertas, 1996). Essas operações se apresentam no plano subdivididas em ações, e estas, em subações, todas acompanhadas de responsáveis, prazos e indicadores de resultados e de execução, o que vai permitir a aferição dos resultados alcançados pela operação em seu todo.

É nesse momento também que a questão dos recursos necessários para realização das operações é considerada, recursos estes que não se referem apenas a bens materiais e monetários, mas também à influência política, a certas habilidades, a conhecimentos pessoais etc. São considerados recursos tudo que seja indispensável à implementação da operação e que tenha de ser analisado quanto a sua disponibilidade (Matus, 1996).

No momento estratégico, analisa-se a viabilidade política do plano, ou se procura construir sua viabilidade, uma vez que nem todas as operações são viáveis na situação inicial. Portanto, o objetivo aqui é propor estratégias para tratar inicialmente as operações não viáveis “... como um processo de produção política em parte cooperativa e em parte conflitiva" (Huertas, 1996). Esse processo se inicia com a construção da matriz de motivações que fornece a posição dos diferentes atores em relação às operações (favorável, desfavorável ou indiferente). Passa então para a avaliação dos recursos necessários à realização de cada operação e para a análise de governabilidade dos atores em relação a esses recursos. Se após esse processo de análise, a operação não se mostrar viável, o passo seguinte é a construção de sua viabilidade por intermédio de estratégias capazes de mudar a realidade da situação sob análise.

Esse, sem dúvida, é o momento de maior complexidade do PES, requerendo quantidade muito grande de informações para a realização de todas as análises previstas. Ainda aqui é analisada a seqüência no tempo das operações, ações e subações, pois essa ordenação pode 
alterar significativamente o plano, levando-o até mesmo à inviabilidade (Matus, 1997a).

O último momento é o tático-operacional e se refere à implementação das ações tendo por referência o plano: "tem a finalidade de criar um processo contínuo, sem ruptura entre os três momentos e a ação diária" (Huertas, 1996). Temse aqui, como mencionado, a necessidade constante de recalcular o plano, aprimorando-o diante das circunstâncias que surgem com sua implementação. Para esse momento o PES dispõe de ferramentas muito interessantes (Matus, 1997a), como os três balanços (de Gestão Política, Macroeconômico e de Intercâmbio de Problemas Específicos) que compõem o denominado Balanço Global de Governo e possibilitam o acompanhamento tecnopolítico da implementação do plano. Sua discussão, no entanto, fugiria ao escopo deste trabalho.

Embora a apresentação tenha sido bastante sucinta, é evidente o grau de desenvolvimento dessa metodologia. É inquestionável, como o próprio Matus (1997b) pondera, que o PES é hoje um corpo teórico-metodológico-prático muito sólido, sistemático e rigoroso. Não só seu trabalho é rigoroso, mas também suas críticas a outras metodologias de planejamento, em particular àquelas que denomina planejamento tradicional $\mathrm{e}$ planejamento estratégico corporativo.

Para esse autor, o planejamento tradicional, que tem origem no determinismo positivista, se baseia no cálculo da predição, constituindo-se basicamente em técnicas de projeções econômicas, as quais, quando utilizadas no planejamento do desenvolvimento econômico e social, ao ignorarem todos os atores do processo social, à exceção do governante, têm caráter autoritário e tecnocrático. Já o planejamento estratégico corporativo, que se volta para empresas e corporações privadas, embora até faça uso do pensamento estratégico, considerando adversários e competidores, e com isso desvalorizando um pouco o cálculo da predição, continua muito influenciado pelo planejamento tradicional: “... $80 \%$ do planejamento estratégico corporativo é determinista e emprega inadequadamente a palavra estratégia" (Huertas, 1996).
Essas críticas, é claro, têm de ser necessariamente relativizadas, pois não fazem justiça à riqueza e à multiplicidade das metodologias atualmente existentes (Rieg, 1999; Pessoa, 2001); chegam até mesmo a ser caricaturescas, na medida em que, por exemplo, se referem a, no máximo, três das dez escolas de formação de estratégias de Mintzberg et al. (2000). Não obstante, há que se reconhecer a vasta herança intelectual deixada por ele, tanto em termos de reflexões acerca do pensamento estratégico e de sua utilidade no jogo social como em termos da criação e do uso de técnicas para a formulação e a avaliação de estratégias. Reconhece-se, além disso, o fato de essa herança intelectual ainda merecer maior atenção acadêmica.

Por outro lado, também é importante ressaltar que todo o rigor e a sistematização pressupostos pelo PES e as informações e o conhecimento necessários acerca da situação e dos atores envolvidos chegam a colocar em dúvida sua aplicação na totalidade. Embora seja inquestionável a importância das informações que a metodologia solicita para a criação e a análise de um plano, também o é a dificuldade para obtêlas. Mesmo que possível, o tempo necessário para obtê-las e processá-las certamente seria incompatível com as agendas e, provavelmente, a motivação dos dirigentes envolvidos. Não obstante, a próxima seção deixa evidente que a utilização, mesmo que parcial, do PES já traz resultados muito interessantes.

Um último ponto a ser ressaltado é a necessidade de relativizar as colocações de Matus (Hertas, 1996), no sentido de identificar o PES como o método e a teoria do Planejamento Estratégico Público; embora seu principal uso venha sendo a problemática pública ou, ainda, o jogo político, econômico e social, nada impede sua utilização em situações em que o mercado faça parte do jogo; ou seja, sua utilização no planejamento de empresas, sejam elas públicas ou privadas. E, inversamente, nada impede que as metodologias denominadas por Matus de corporativas sejam utilizadas em contextos públicos. 


\section{O PES na UFSCar}

É importante, inicialmente, salientar que a construção do planejamento estratégico para a Gestão da UFSCar 1996-2000 (Relatório, 1997) se deu em conjunto com a Escola de Governo da Unicamp e contou com o apoio do CNPq, por intermédio do Programa Temático Multi-Institucional em Planejamento e Gestão, ProTeMPG/CNPq.

A equipe da Escola de Governo da Unicamp, de acordo com Fortes (1997b), vem desde sua criação procurando incorporar a avaliação crítica de uma grande diversidade de instituições e consultores e suas experiências de utilização de diferentes métodos de planejamento estratégico. Assim, embora faça uso intensivo do PES, também utiliza o método ZOPP (Planejamento Participativo Orientado por Objetivos) da GTZ - instituição de cooperação internacional alemã - e do PAE (Planejando a Ação Estratégica). Faz uso, além disso, de outras técnicas desenvolvidas pela própria escola para lidar com as especificidades das diferentes situações. A característica contingencial das metodologias de planejamento atualmente é inquestionável (Pessoa, 2001) e, como pondera Fortes (1997b), o planejador deve conceber os métodos mais como "caixas de ferramentas", cujos recursos devem ser adaptados às situações conforme elas emergem, do que como roteiros rígidos a serem seguidos em qualquer situação.

Assim, embora o plano estratégico desenvolvido para a UFSCar leve em conta principalmente os conceitos da "teoria PES", ele também incorpora todas essas experiências mais gerais do grupo da Escola de Governo, adaptando-as às circunstâncias da UFSCar, das quais foram consideradas como mais importantes: (i) o grupo envolver 40 pessoas de todas as áreas de gestão; (ii) a necessidade de ganhar adesão da equipe ao processo logo no início; (iii) o prazo de três meses para ter um documento elaborado e divulgado; (iv) as próprias críticas à rigidez do PES; (v) a limitação de recursos financeiros e humanos; e (vi) a possibilidade de deixar questões para serem aprofundadas durante a implementação.
Assim, trabalhou-se coletivamente com a equipe de gestão para identificar a "fotografia" da UFSCar que a mesma pretendia para o ano 2000, o que deu corpo à formulação do projeto de gestão. A partir daí procurou-se, sempre coletivamente e utilizando a técnica de cartões (Fortes, 1997a), identificar os principais desafios a serem enfrentados pela gestão em busca do referido projeto.

Nessa etapa foram considerados não só os aspectos sociopolíticos e econômicos da época, mas também as possibilidades que se prenunciavam para as IFES, além do contexto interno à UFSCar. Nesse sentido, inclusive, alguns palestrantes foram trazidos para discutir com a equipe dirigente. $\mathrm{O}$ uso inicial da idéia de desafios possibilita que a equipe planejadora possa expressar e compartillhar, logo no ínicio dos trabalhos, as questões que considera centrais a serem enfrentadas, tenham elas caráter positivo ou negativo (Fortes, 1997a).

Escolhidos os principais desafios a serem enfrentados (sete ao todo), os quais passaram a constituir o foco estratégico do plano, foram definidos os respectivos descritores de resultados, ou seja, aquilo que se pretendia obter com a execução do plano. Partiu-se, então, para a seleção dos problemas a serem enfrentados e, dessa seleção, foi construído um rico fluxograma situacional envolvendo cerca de 80 problemas. A partir daí foram seguidos os passos descritos na seção anterior para os momentos 1 e 2 do PES, ou seja, a identificação dos nós críticos e o delineamento das operações necessárias para enfrentá-los.

Foram definidas 19 operações, sendo que para seu detalhamento, ou seja, para definição das ações e subações, respectivos responsáveis, datas-limite e indicadores de execução, a equipe dirigente foi subdividida nas quatro grandes áreas da universidade: ensino, pesquisa, extensão e administração. Os resultados desse detalhamento foram então submetidos à apreciação do grupo geral para análise de viabilidade estratégica, estabelecendo-se, novamente, um rico processo de discussão. A partir daí, a UFSCar passou a atuar tendo por referência esse plano, com um grupo de professores e técnicos 
responsáveis pelo monitoramento de cada uma das operações, sendo que a equipe reunia-se anualmente para avaliar o andamento do plano.

Pode-se observar, então, que, na verdade, a aplicação do PES distanciou-se da forma preconizada por Matus (1997b), não tanto pelo conteúdo, mas muito mais pelo rígido formato por ele preconizado. Para a Pró-Reitoria de Extensão, duas grandes operações foram concebidas: "Incrementar a atuação extensionista da UFSCar integrada ao conjunto da prática acadêmica e à atuação artístico-cultural" e "Implementar diferentes canais de captação de demandas". No Quadro 1 apresenta-se de forma esquemática uma parte da primeira operação (Operação 6 no Plano).

\section{Mapeamento Cognitivo}

O Mapeamento Cognitivo (Eden et al., 1979, 1983) faz parte de um conjunto de metodologias que dá corpo ao que hoje se convencionou denominar abordagem soft da Pesquisa Operacional (PO) e que se volta muito mais para a estruturação de situações problemáticas complexas, auxiliando no discernimento de estratégias, do que para sua resolução propriamente dita nos moldes da abordagem convencional da PO (Rosenhead, 1989; Araújo Filho, 1994, 1995). Caracterizandose também por uma abordagem subjetiva, o mapeamento procura representar a percepção dos indivíduos envolvidos em uma situação problemática, fundamentando-se na Teoria dos Constructos Pessoais da área de psicologia (Kelly, 1955; Pidd, 1996). Diferencia-se, inclusive, em função dessa fundamentação, de outras abordagens de mapeamento que vêm sendo desenvolvidas (Huff, 1990; Fiol \& Huff, 1992).

De acordo com essa perspectiva, os indivíduos estão continuamente se esforçando para dar sentido às situações por eles enfrentadas e, dessa forma, atribuindo significados a eventos e experiências. Fazendo isso, buscam antecipar as consequiências daquilo que estão vivenciando e se preparar para enfrentá-las e obter o que desejam. Para atribuir significados a eventos e experiências, fazem uso de seus sistemas de constructos (conceitos), os quais são as idéias ou informações verbalizadas pelos indivíduos, que no mapa tomam a forma de frases (de até no máximo dez, doze palavras). Considerando que os constructos podem ser superiores ou inferiores a outros, eles são dispostos hierarquicamente, formando um

Quadro 1 - Quadro parcial de uma das operações resultantes do plano desenvolvido pelo PES.

\begin{tabular}{|c|c|c|c|}
\hline Operação & Resp. & Prazo & Indicador de resultado \\
\hline $\begin{array}{l}\text { 6. Incrementar a atuação extensionista } \\
\text { integrada ao conjunto da prática } \\
\text { acadêmica e à atuação artístico- } \\
\text { cultural. }\end{array}$ & & & $\begin{array}{l}\text { Atuação nos diferentes segmentos sociais; } \\
\text { articulaçãa com pesquisa; } \\
\text { articulação com ensino de graduação e pós- } \\
\text { graduação; } \\
\text { ampliada a atuação artístico-cultural. }\end{array}$ \\
\hline Ação & Resp. & Prazo & Indicador de execução \\
\hline $\begin{array}{l}\text { 6.1 Aperfeiçoar os mecanismos } \\
\text { organizacionais para a extensão. }\end{array}$ & & & $\begin{array}{l}\text { Núcleos e coordenações estruturados com } \\
\text { espaço físico e pessoal; } \\
\text { ampliado o número de projetos propostos e } \\
\text { articulados pelos escritórios regionais e } \\
\text { núcleos de extensão. }\end{array}$ \\
\hline
\end{tabular}

6.1.1 Implantar infra-estrutura e condições para o funcionamento do trabalho dos núcleos e coordenações. 6.1.2 Consolidar núcleos de extensão e escritórios regionais. 
sistema. Esse sistema, que pode envolver metas, objetivos, explicações, problemas, oportunidades, necessidades, imposições, fatos, estratégias etc., se constitui em uma forma de representar como cada indivíduo vivencia o mundo e se comporta diante dos acontecimentos.

Ligando os constructos, têm-se os arcos direcionados, os quais, embora façam o mapa parecer um diagrama de causa e efeito, buscam representar não só esse tipo de relacionamento mas também a conexão de explicações a conseqüências, opções a resultados, ações a objetivos, todas orientadas pela lógica de que os resultados, fins e objetivos mais importantes são hierarquicamente superiores no mapa. A Figura 4 apresenta uma parte simplificada de um dos mapas construído para (e com) o cliente do trabalho que este artigo apresenta - o pró-reitor de extensão da UFSCar.

Observa-se, então, que, além da ordenação entre conceitos (microordenação), o mapa apresenta uma ordenação de caráter mais macro (Ackermann et al., 1991), ou seja, o mapa pode ser visto como um conjunto de camadas: no topo o conjunto de metas do indivíduo; mais ao centro, conceitos que sugerem possíveis direções estratégicas; e abaixo destes, as opções que potencialmente podem viabilizar tais direções. Permeando essas três camadas tem-se todo o detalhamento, em termos de exemplos, explicações, opções e mesmo ponderações, que fundamenta a argumentação e as reflexões de quem relata o problema e torna o mapa um modelo de riqueza inquestionável (Rieg, 1999).

Assim, na Figura 3, o conceito 44 pode ser visto como uma direção estratégica. Acima dele há as metas que o cliente do problema busca alcançar com tal direção (no caso, ao discutir com os departamentos seus programas de extensão a expectativa do cliente é a de que essa discussão tenha como conseqüência os conceitos 19, 20, 124, 30, 42 e 47); e, abaixo, um conjunto de opções para viabilizá-la. Já no nível mais micro, a Figura 3, embora já simplificada, ilustra o grau de riqueza e detalhe que a representação gráfica possibilita. Nesse sentido, inclusive, é fundamental salientar que um mapa, sendo produto de profundo processo interativo entre mapeador e cliente, ao procurar representar de forma organizada como este último percebe determinada situação, ele, na maioria das vezes, não fará sentido para alguém externo ao processo de sua criação. Os recortes no mapa da Figura 4 foram feitos a fim de torná-lo minimamente inteligível para outros. Outras considerações mais específicas e detalhadas acerca do conteúdo e da estrutura e mesmo sobre a construção de um mapa podem ser encontradas em Rieg (1999). Além disso, as potencialidades e as possibilidades de seu uso na prática serão abordadas nas seções seguintes.

Para concluir esta seção, cabe observar que, embora este trabalho se atenha à utilização do mapeamento cognitivo com (e por, como se verá) um único indivíduo, ele, na verdade, é a principal técnica utilizada pela metodologia Strategic Options Decision \& Analysis (SODA) para o trabalho com grupos (Eden \& Radford, 1990). De forma sucinta, trabalha-se inicialmente com cada indivíduo do grupo, construindo seus respectivos mapas, para, então, em workshops trabalhar com a agregação desses mapas e, assim, avançar no processo de conseguir uma visão acordada acerca da situação em questão e maior comprometimento do grupo na implementação do conjunto de ações identificadas como relevantes (Eden, 1989).

\section{Aplicação do Mapeamento Cognitivo na Pró-Reitoria de Extensão da UFSCar}

Primeiramente, é importante salientar que o trabalho, não só aqui com o mapeamento mas também com o PES, foi bastante facilitado pelo fato de o pró-reitor, tendo interesse acadêmico na área, ter sido não só objeto (cliente), mas também sujeito das aplicações. No início de seu mandato, em janeiro de 1997, ele realizou estágio na Inglaterra, oportunidade em que, aprendendo a trabalhar com o mapeamento, construiu um mapa envolvendo um plano de ação para suas atividades na Pró-Reitoria (ProEx1). 


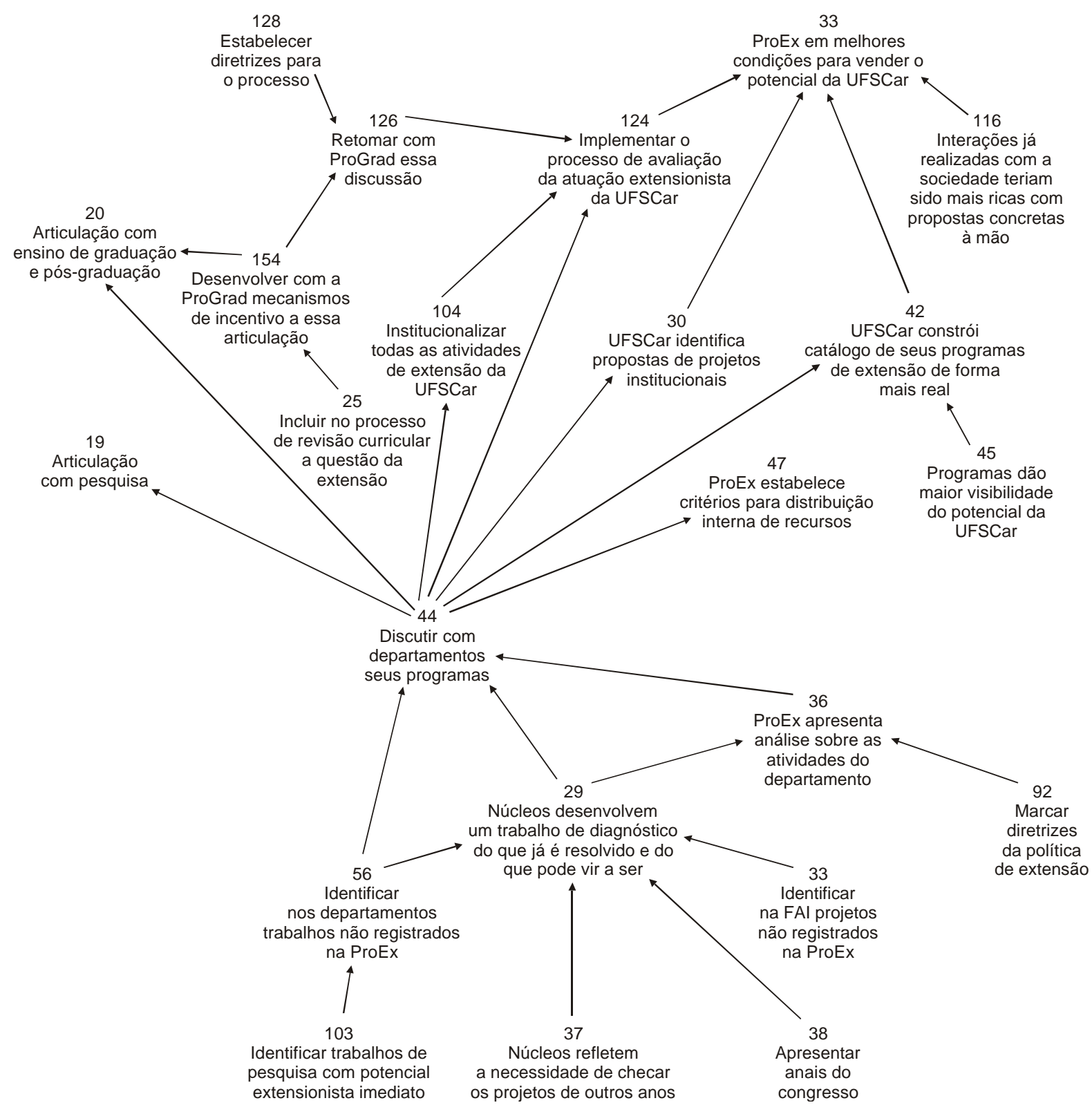

Figura 3 - Representação de parte de um mapa cognitivo.

O processo de criação desse mapa, bem como os ganhos advindos de sua criação são discutidos em Cropper \& Araújo Filho (1999) e Araújo Filho (1999). Aqui cabe apenas destacar alguns aspectos. Primeiro, o reconhecimento de que o ato de mapear constitui-se em uma rica experiência, pois ao fazer com que o conhecimento do cliente venha à tona, sendo então estruturado e validado, ele põe em cheque de forma muito objetiva crenças e questões que muitas vezes se assumem como dadas. Como reconhece o cliente (Araújo Filho, 1999), mesmo tendo consigo documentos sobre a extensão, além de naturalmente suas próprias crenças, ele foi surpreendido e, muitas vezes, não conseguia avançar ao se defrontar com as questões que comumente são feitas durante o mapeamento (Rieg \& Araújo Filho, 1999): "como esse conceito se liga a outro?", "por quê?" (no sentido de esse conceito leva a quê?), "por que fazer isso?", "como fazer isso?". 


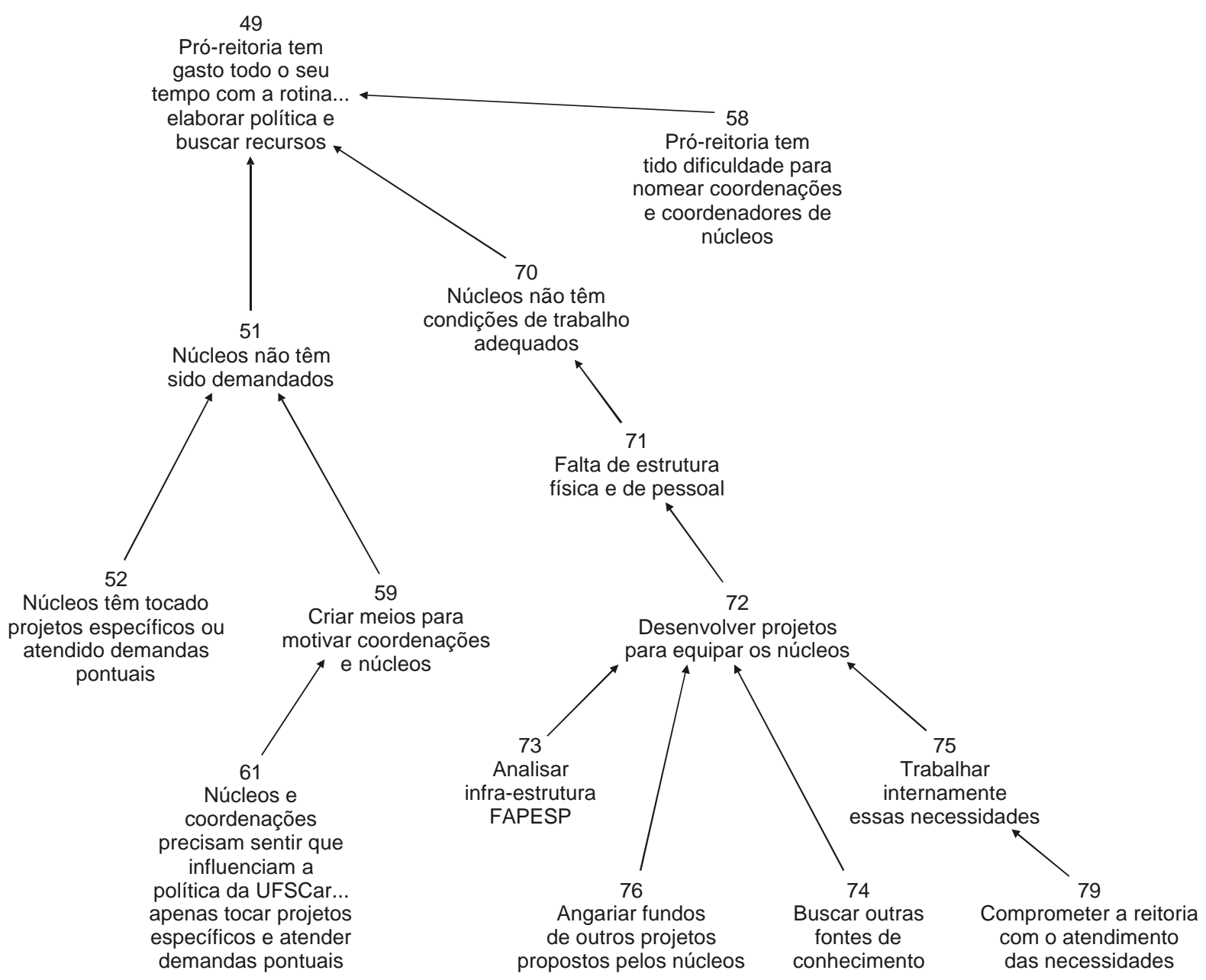

Figura 4 - Parte do ProEx3 relativo à subação 6.1.2.

Conscientizou-se de que não só os documentos, mas seu próprio conhecimento, estavam permeados por questões ainda não bem definidas e até mesmo por "chavões", os quais, sendo questionados pelo mapeamento, o forçavam a criar novas (e mais adequadas a seu ver) interpretações para os temas tratados.

Decorrente também desse intenso processo de reflexão tem-se a retenção pelo cliente das linhas de argumentação, representadas pelas ligações entre os conceitos. Como ele mesmo pondera, em muitas situações, quando tinha de fazer intervenções (e até mesmo discursos improvisados) ou defender sua perspectiva quanto ao porquê e como investir na extensão, ele se lembrava das linhas de argumentação, como se tivesse acabado de construir o mapa.

Quanto ao conteúdo do ProEx1, um vasto conjunto de temas é abordado, no entanto, sem aprofundamento. Não se constitui em uma listagem detalhada de ações, mas “... muito mais em uma representação estruturada daquilo que o pró-reitor via como mais importante para ser realizado e, nesse sentido, uma referência a partir da qual suas decisões poderiam ser tomadas" (Rieg, 1999). Embora ele pudesse ter sido utilizado de forma mais efetiva, como comentado a seguir, como o cliente tinha em mente trabalhar com o mapeamento com seu grupo de alunos, para fins de comparação e 
complementação da utilização do PES, o ProEx1 não foi mais manuseado. Na verdade, ele só voltou a ser utilizado no final da gestão, quando se procurou avaliar os impactos da construção dos diferentes mapas. Esse momento, inclusive, surpreendeu o cliente, pois o ProEx1, mesmo com grande parte das questões específicas encaminhadas, superadas ou até mesmo se tornado obsoletas em função das mudanças do ambiente, dado seu caráter estratégico, não tinha perdido "atualidade"; essa questão será retomada posteriormente.

Cabe salientar que, em função do tipo de retenção mencionado, o ProEx1 se constituiu, na verdade, em uma ferramenta de conversação do cliente consigo mesmo e com outros envolvidos (tanto interna como externamente à universidade) - sobre a questão da extensão universitária e da função do cliente com o gestor na UFSCar (Araújo Filho, 1999). Propiciou, além disso, quando retornou do estágio, maior confiança e satisfação para dar continuidade a sua função, sentimentos que Eden \& Ackermann (1998) consideram decorrentes não só do conhecimento adquirido com o ato de mapear, mas também do comprometimento decorrente.

A partir de abril de 1997, passou a ocorrer experiência já relatada de construção do plano PES, que se estendeu até julho do mesmo ano. Naturalmente, nesse período, mesmo não tendo sido manuseado, mas pelas razões já expostas, o ProEx1 subsidiou as participações do cliente na criação do plano PES para sua pró-reitoria.

Embora ao longo desse período o grupo acadêmico do cliente já o auxiliasse com a construção de mapas sobre temas específicos, foi só no segundo semestre de 1997 que se iniciou a experiência com o PES e o mapeamento, tendo por objetivos: (i) verificar como o mapeamento poderia enriquecer a agenda de ações da ProEx por meio do PES; (ii) desenvolver formas para o uso do mapeamento na implementação e na monitoração do plano PES; e (iii) procurar discernir possibilidade de complementação entre o mapeamento e o PES.

$\mathrm{O}$ primeiro passo foi, dada a agenda PES para as duas operações da ProEx, procurar enriquecê- la construindo a partir dela, isto é, a partir das ações, subações, indicadores de resultados etc. incluídos, um novo mapa que a contextualizasse melhor. Essa expectativa era fruto da observação não só com nosso cliente, mas também com outros membros da equipe dirigente da UFSCar, responsáveis por outras operações, que muitas vezes apresentavam dificuldades em interpretar as razões de várias ações ou subações fazerem parte da agenda; não só as razões mas também as relações entre elas. Assim, foi pressuposto que a construção do mapa, ao contextualizar esse conjunto de informações, poderia não só facilitar a visualização do cliente acerca da temática, mas possibilitar que novas reflexões e, portanto, novas estratégias e ações pudessem emergir.

No entanto, duas dificuldades tiveram de ser superadas (Rieg, 1999). A primeira delas foi oriunda da inexperiência do grupo com a utilização do mapeamento e também de sua pouca vivência, na prática, com problemas organizacionais (o grupo era composto por mestrandos sem muita experiênca com trabalho profissional e alunos de iniciação científica). Salienta-se que, enquanto o mapa ProEx1 foi construído pelo próprio cliente, o segundo mapa (ProEx2), tendo também finalidades didáticas, foi construído pelo grupo de alunos que atuavam como facilitadores. Assim, embora o mapeamento não requeira que $o$ facilitador domine tecnicamente o assunto em tela, desempenhando o papel de consultor (Eden \& Sims, 1979), ele, sem dúvida alguma, requer certa 'maturidade' organizacional, além de algum domínio ou experiência com o trabalho de facilitação desses processos de interação. Só com o tempo e com a realização de várias experiências é que essa dificuldade foi superada.

A segunda dificuldade foi fruto da adoção da agenda PES como uma referência extremamente rígida, isto é, de tentar reproduzir no mapa todos os elementos da agenda, exatamente como eles se apresentavam, inclusive em suas relações hierárquicas (indicador de execução da subação $\Rightarrow$ subação $\Rightarrow$ indicador de execução da ação $\Rightarrow$ ação $\Rightarrow$ indicador de resultado da operação $\Rightarrow$ operação). Essa "fidelidade" à agenda PES, aliada à inexperiência não só com a técnica mas 
também com a vida organizacional, na verdade, funcionou como uma camisa-de-força para os avanços em termos do mapa que se buscava construir. Essa dificuldade só foi superada quando se flexibilizou a adoção da agenda PES como referência.

Não obstante essas dificuldades, ressalta-se que essas tentativas e as diferentes versões do mapa ProEx 2 foram extremamente valiosas para o cliente, pois foi por meio delas que se deu o discernimento daquela que foi uma das principais ações de sua gestão - a implementação dos programas de extensão na UFSCar. Ou seja, mesmo com as dificuldades, o processo, por demandar intensas reflexões, se mostrou importante para o cliente.

O mapa ProEx3, construído após a flexibilização da agenda PES, contendo cerca de 300 conceitos, reuniu parte significativa do conhecimento acumulado pelo cliente em seus 18 meses de gestão, apresentando grau de contextualização das ações, em termos de por que realizá-las, de suas relações com as demais e das opções para alcançá-las, muito maior do que a dos mapas anteriores e, principalmente, maior do que a do plano PES. A comparação entre o Quadro 1, relativo à agenda do PES, e a Figura 4 ilustra esse aspecto. No Quadro 1 tem-se parte do plano, em que uma ação está subdividida em duas subações; já a Figura 4 apresenta a parte do mapa ProEx3 relativa a uma dessas subações (implementar infraestrutura e condições para o funcionamento do trabalho dos núcleos de extensão).

Essa subação, por parecer óbvia, em princípio, não foi subdividida em tarefas na agenda. Pode-se observar, no entanto, na Figura 4 que, de um lado, na medida em que essa atividade depende de recursos financeiros, depende conseqüentemente da identificação de fontes alternativas de custeio e de trabalho interno "ganhando o comprometimento" da reitoria. As opções não apresentadas na figura ligam-se a outras estratégias, ilustrando que a questão dos recursos para viabilizar a extensão depende de políticas mais amplas, incluindo a revisão das taxas incidentes sobre os projetos. De outro lado, pode-se observar que a falta de estrutura física e de pessoal leva a Pró-Reitoria a despender seu tempo com atividades rotineiras, em detrimento da elaboração de políticas e da busca de recursos, o que, por sua vez, além de outras explicações, também tem outras implicações não mostradas na Figura 4.

Embora a partir desse mapa mais geral tenhase tentado construir uma agenda formal nos moldes do PES (Rieg, 1999), observou-se que esta, quando comparada com o mapa, não seria capaz de reproduzir sua riqueza. Assim, passouse a explorar a possibilidade de utilizar partes do mapa como agendas, trabalho este bastante facilitado pelo software do mapeamento Decision Explorer -, indispensável quando um mapa passa a ter mais de 50 conceitos, pois já começa a ficar inviável seu manuseio em papel (Eden, 1989).

O trabalho procurou adaptar e desenvolver alguns mecanismos que facilitassem o uso do mapa pelo cliente na forma de agenda, de modo a dar-lhe condições para que, ao explorá-la, pudesse adquirir uma visão do andamento do plano. Trabalho este conduzido em conjunto com o cliente a fim de garantir que o mesmo atendesse a suas necessidades.

Basicamente, criou-se uma agenda em que as ações mais importantes estrategicamente foram destacadas, utilizando cores e classificando-as de acordo com o estado no qual cada ação se encontrava: ações já realizadas $(\mathbf{R})$; ações em execução que já possuíam os recursos alocados $(\mathbf{S})$; ações em execução com recursos ainda insuficientes (\#) etc. Assim, conseguiu-se um mecanismo rápido e eficiente para monitoração do plano.

Para facilitar esse tipo de monitoração, que seria complexo em razão da dimensão do mapa, este foi subdivido em grupos de conceitos por assuntos específicos, tornando-se cada grupo uma 'vista' diferente (um dos recursos do Decision Explorer que permite que o mapa seja decomposto e apresentado por partes (vistas) ao usuário). Outro recurso utilizado foram os memos, pequenos arquivos que podem ser alocados aos conceitos e nos quais é possível inserir qualquer tipo de informação. Assim, sempre que necessário, adicionou-se memos às ações, registrando-se 
prazos e responsáveis, reuniões a serem realizadas, recursos ainda necessários etc. Essas informações, cabe observar, eram facilmente recuperáveis, já que o software por meio de comandos específicos lista todos os conceitos ou memos que contêm a palavra ou caractere procurado. Assim, se o cliente desejasse saber quais ações haviam sido realizadas, bastaria realizar uma pesquisa com o símbolo $(\mathbf{R})$.

Dessa forma, esse tipo de agenda com o formato de mapa veio a facilitar os processos de implementação e monitoração do plano, sendo bastante simples para o cliente alterá-la de acordo com as circunstâncias enfrentadas. Dada a simplicidade do software, o cliente pôde passar a utilizá-lo em seu dia-a-dia, de forma independente dos mapeadores.

Um último ponto que merece ser destacado diz respeito a não utilização do mapa ProEx1 como uma das referências utilizadas pelo grupo que trabalhou como facilitador e/ou mapeador. Há que se ter claro, nesse sentido, que o ProEx1, como já mencionado, não perdeu sua atualidade durante toda a gestão; constituia-se, por conseguinte, em uma fonte de informações relevante que poderia ter sido melhor utilizada. Pelo fato de ter sido construído em momento inicial da gestão (terceiro mês), quando o cliente ainda não conhecia bem o ambiente organizacional em que estava se envolvendo, ele talvez pudesse ter sido de mais fácil compreensão para o grupo facilitador, que poderia acompanhar a evolução do pensamento e do conhecimento do cliente. Embora a comparação entre os mapas tenha sido realizada a posteriori (Rieg, 1999; Pessoa, 2001), torna-se evidente a evolução positiva do conhecimento do cliente.

A Figura 5 apresenta a parte do ProEx1 que aborda os programas de extensão, os quais constituíram-se em uma das principais estratégias do cliente. Como contraponto, tem-se a Figura 1, que apresenta o tratamento bem mais detalhado que esse tema recebe no ProEx3.

Essa evolução ocorre no sentido de maior detalhamento das ações propostas, do que se busca com elas e de como realizá-las, detalhamento este mais pautado na realidade organizacional. Mesmo não se tendo o registro dos momentos em que as alterações se processaram, é evidente que os mapas passam a ter maior objetividade e clareza de intenções e explicações, demonstrando que o conhecimento do cliente adquire formas mais estruturadas e leva a ações mais coerentes que foram concretamente implementadas.

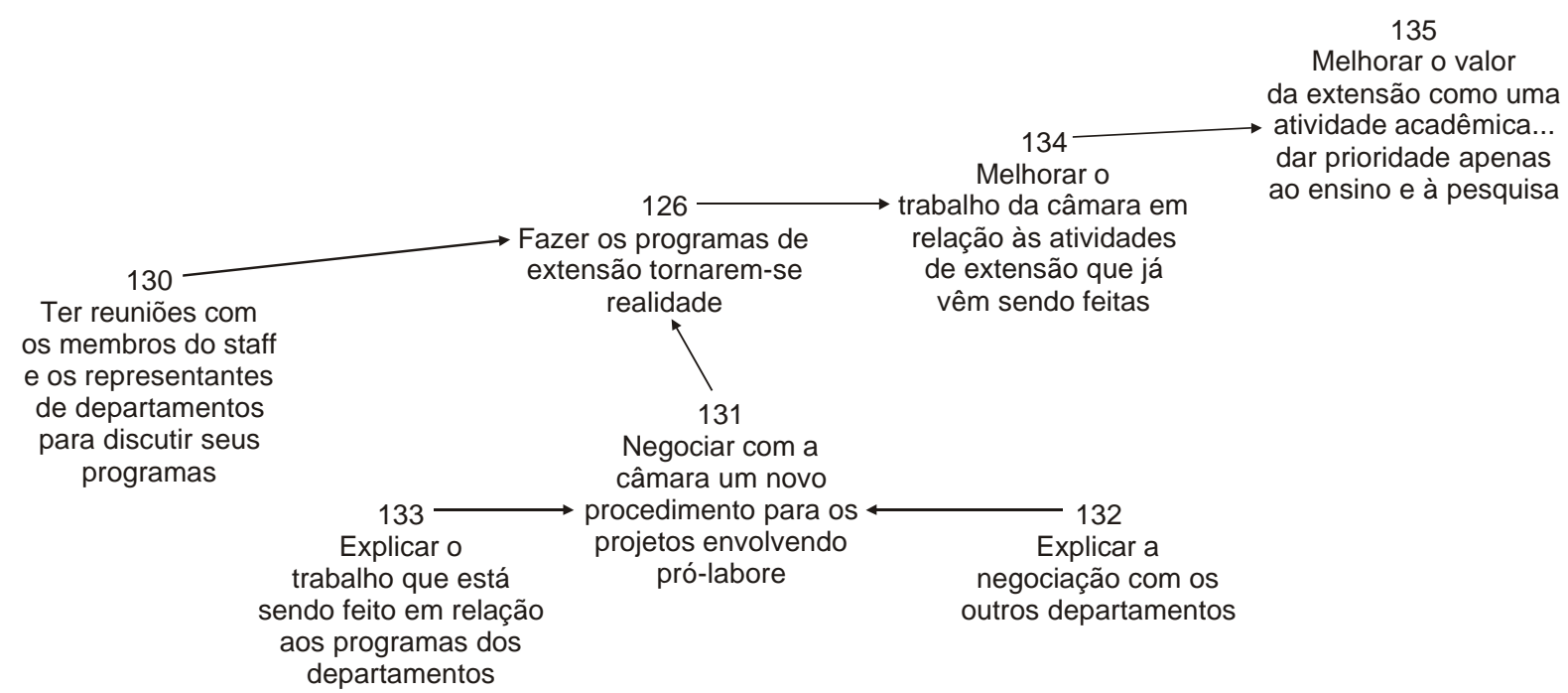

Figura 5 - Parte do ProEx1 relativa aos programas de extensão. 
Entretanto, como comenta Rieg (1999), essa evolução “... não aparece de forma objetiva nos mapas, tudo se passa como se o cliente, retendo os conhecimentos já registrados e deparando-se com a realidade, os reestruturasse em sua mente". Com base nesses resultados, pôde-se perceber que, se o conteúdo desses mapas tivesse sido utilizado, este processo, que parece ter ocorrido por 'osmose', poderia ter sido otimizado, “... facilitando o processo de criação e visualização pelo cliente das formas mais adequadas para implementação de suas estratégias".

É importante que se observe que aqui não se busca formalizar o processo e dessa forma perder, como pondera Mintzberg (1987), a capacidade de síntese tão necessária à formação de estratégias.

Pelo contrário, o que se pondera aqui é que o uso mais sistemático dos mapas pode ser importante, não só para a monitoração do plano, mas também para incrementar o processo de aprendizagem que ocorre quando se implementa um plano e se tem, então, que rever, aprimorar e mesmo abandonar as estratégias concebidas. Tem-se, assim, uso do mapeamento tanto como um mecanismo para o desenvolvimento de estratégias quanto como um mediador do processo de aprendizagem do cliente, em que o mapa media os processos do pensar para o agir e do agir para o pensar, ou seja, da reflexão e ação e da ação e reflexão (Kolb \& Rubin, 1991).

\section{Considerações finais}

Como na criação de um plano estratégico tanto o processo como o produto são importantes e situacionais, torna-se muito difícil reproduzir com fidelidade os detalhes de todo o desenvolvimento, em particular quando se têm metodologias como as aqui apresentadas, que podem ser consideradas processualistas (Whittington, 1993), isto é, em que as estratégias emergem em função de processos de aprendizagem e adaptação.

Em relação à aplicação do PES, há que se ressaltar seu forte impacto positivo sobre o trabalho da gestão. De acordo com membros da equipe que tinham participado da gestão anterior (Santos, 2001), em que o planejamento foi desenvolvido nos moldes mais convencionais, a riqueza das discussões orientadas pelas diretrizes da metodologia criou, por si só, um clima de maior compartilhamento e comprometimento, principalmente na fase de concepção do plano. Já em termos do quarto momento, dispunha-se de material muito importante para o monitoramento da implementação das ações. Embora não se tenha feito uso nesta fase das ferramentas preconizadas pelo PES, o acompanhamento periódico de como e por que as ações estavam sendo implementadas também foi muito importante. Igualmente importantes foram os momentos anuais quando toda a equipe se reunia para avaliar o andamento do plano e rever as ações previstas.

Já em termos da Pró-Reitoria de Extensão, como se viu, as operações derivadas da aplicação do PES foram bastante enriquecidas com a utilização do mapeamento cognitivo. Na verdade, procurou-se ilustrar não só essas possibilidades de enriquecimento, mas também apresentar os meios desenvolvidos para utilização do mapeamento na implementação e monitoração do plano. Ressaltase, nesse sentido, dado que a agenda PES não difere significativamente das agendas resultantes de outras metodologias de planejamento, que podem, assim, se ressentir de melhor contextualização de suas ações e subações, a probabilidade de a utilização do mapeamento enriquecer os processos dessas outras metodologias também.

Sendo pragmáticos, que é a postura que em geral se tem em relação às metodologias de planejamento, pode-se ponderar que as duas metodologias mostraram-se efetivas no que diz respeito a auxiliar o tomador de decisões em seu trabalho. Enquanto a apresentação do PES, que teve seu foco em um grupo de decisores, chama a atenção para a necessidade de olhar com mais atenção os conceitos e as técnicas que dele fazem parte, a apresentação do mapeamento, voltada para um único ator, e naturalmente beneficiada pelas circunstâncias que possibilitaram uma exploração mais aprofundada, 
deixou evidente as potencialidades deste como ferramenta para formulação e desenvolvimento de estratégias.

Em um patamar mais teórico, são várias as possibilidades de complementaridade entre o Mapeamento Cognitivo e o PES. Da mesma forma que o mapeamento é utilizado como uma técnica da SODA, como foi visto, ele poderia ser utilizado com os indivíduos pertencentes ao grupo planejador, antes de realizar as reuniões para definição do macroproblema e do fluxograma situacional; este último, inclusive, é uma árvore causal, que apresenta semelhanças com mapas cognitivos. Tanto o enriquecimento das agendas como o acompanhamento do plano foram aqui abordados, sendo apresentado um formato alternativo de agenda por meio de mapas que, para o cliente em questão, se mostrou mais interessante. Por fim, a análise da viabilidade política do plano no PES poderia certamente ser conduzida nos moldes de um SODA Workshop (Eden \& Radford, 1990).

Em suma, as possibilidades de o mapeamento enriquecer o PES se dão nos quatro momentos. $\mathrm{O}$ contrário, embora não tenha sido explorado aqui, também é possível, pois muitas das técnicas do PES poderiam auxiliar no mapeamento, como como ocorre com a Metodologia da Escolha Estratégica (Friend \& Hickling, 1987), cujos pacotes de comprometimento são, às vezes utilizados como agendas dos resultados da aplicação da SODA ou do mapeamento. Há que se ter sempre em mente o caráter contingencial que a abordagem de planejamento requer.

\section{Referências Bibliográficas}

ACKERMANN, F.; CROPPER, S.; EDEN, C. Cognitive mapping for community operational research: a user's guide. Tutorial Paper. Birmingham: O. R. Society, 1991.

ACKOFF, R. L. Redesigning the future. New York: Wiley, 1974.

ARAÚJO FILHO, T. Revisão dos mapas da ProEx. UFSCar, mimeo, 1999.

ARAÚJO FILHO, T. Ampliando os horizontes da PO: métodos para estruturação de problemas. In: ENEGEP, 15., 1995, São Carlos. Anais... São Carlos: UFSCar, 1995.

ARAÚJO FILHO, T. A abordagem soft da pesquisa operacional: discussão e aplicação ao processo de implantação do sistema AIH. 1994. Tese (Doutorado) COPPE-UFRJ, Rio de Janeiro.

ARAÚJO FILHO, T.; FUKS, S. A abordagem soft da PO: um desdobramento da evolução da PO. In: ENEGEP, 14., 1994, João Pessoa. Anais... João Pessoa: UFPb, 1994.

CROPPER, S.; ARAÚJO FILHO. Conceptions of managerial learning: a case history. In: EGOS European Group of Organizational Studies, 15., 1999. Warwick. Proceedings... CD-ROM, Warwick, 1999.
EDEN, C. Using cognitive mapping for strategic options \& development analyis. In: ROSENHEAD, J. rational analisys for a problematic world. London: Wiley, 1989. p. 21-42.

EDEN, C.; ACKERMANN, F. Making strategy: the journey of strategic management. London: Sage, 1998.

EDEN, C.; RADFORD, J. Tackling strategic problems. London: Sage, 1990.

EDEN, C.; SIMS, D. On the nature of problems in consulting practice. Omega, v. 7, n. 2, p. 119-27, 1979. EDEN, C.; JONES, S.; SIMS, D. Messing about in problems. London: Pergamon, 1983.

EDEN, C.; JONES, S.; SIMS, D. Thinking in Organizations. London: Macmillan Press, 1979.

FIOL, C. M.; HUFF, A. S. Maps for managers. Where are we? Where do we go from here? Journal of Management Studies, v. 29, n. 3, p. 267-86, 1992. FORTES, A. Caderno de conceitos. UFSCar, mimeo, 1997a.

FORTES, A. Sistematização: a experiência do planejamento estratégico da UFSCar - gestão 19962000, UFSCar, mimeo, 1997b.

FRIEND, J. K.; HICKLING, A. Planning under pressure: the strategic choice approach. Oxford: Pergamon, 1987. 
HUERTAS, F. Entrevista com Matus. São Paulo: FUNDAP, 1996.

HUFF, A. S. Mapping strategic thought. New York, 1990.

KELLY, G. A. The psychology of personal constructs: a theory of personality. New York: Norton, 1955.

KOLB, D.; RUBIN, L. M. Organizational Behaviour: an experiential approach. New Jersey: Prentice Hall, 1991.

MASON, R. O.; MITROFF, I. I. Challenging strategic planning assumptions. New York: Wiley, 1981.

MATUS, C. Estratégias políticas. São Paulo: FUNDAP, 1996.

MATUS, C. O Método PES: roteiro de análise teórica. São Paulo: FUNDAP, 1997b.

MATUS, C. Teoría de la producción y el juego social. Isla Negra: Altadir, 1998.

MATUS, C. El lider sin Estado Mayor. La Paz: Altadir, 1997a.

MINTZBERG, H. Crafting strategy. Harvard Business Review, jul.-ago., 1987.

MINTZBERG, H.; AHLSTRAND, B.; LAMPEL, J. Safari de estratégias: um roteiro pela selva do planejamento estratégico. Tradução Nivaldo Montigelli Jr. Porto Alegre: Bookman, 2000.
PESSOA, M. B. D. O uso do mapeamento cognitivo como ferramenta de planejamento estratégico. Exame de Qualificação, São Carlos: UFSCar, 2001. PIDD, M. Tools for thinking. London: Wiley, 1996. RELATÓRIO do Planejamento estratégico da UFSCar 1997-2000, mimeo, 1997.

RIEG, D. L. Planejamento estratégico: uso das metodologias "Mapeamento Cognitivo e Planejamento Estratégico Situacional" em uma situação concreta. Tese (Doutorado) - UFSCar, São Carlos.

RIEG, D. L.; ARAÚJO FILHO, T. Mapeamento cognitivo como ferramenta para desenvolvimento, implementação e monitoração de estratégias. In: ENEGEP, 19., 1999. Niterói. Anais... Niterói: UFF, 1999. ROSENHEAD, J. Rational analysis for a problematic world. Londres: Wiley, 1989.

SANTOS, A. C. A Aplicação do PES na UFSCar. Exame de Qualificação. São Carlos: UFSCar, 2001. WHITTINGTON, R. What is strategy and does it matter? London: Routledge, 1993.

\section{THE USE OF THE METHODOLOGIES "SITUATIONAL STRATEGIC PLANNING" AND "COGNITIVE MAPPING" IN A CONCRETE SITUATION: THE CASE OF THE EXTENSION PRO-DEANSHIP OF UFSCAR}

Abstract

This work discusses two strategic planning methodologies "Situational Strategic Planning (PES)" and "Cognitive Mapping", having as a reference the application of them in a concrete situation - the management of the Extension Pro-Deanship of UFSCar. In this sense, it presents some considerations about the contents and structures of these two methodologies, and a discussion about their implementation. Besides it, the work develops some complementarity possibilities between them.

Key words: cognitive mapping, situational strategic planning, case study, complementarity. 